\title{
Fiscal policy and interest rates: the role of financial and economic integration*
}

\author{
By Peter Claeys, Rosina Moreno and Jordi Suriñach \\ AQR Research Group - IREA. Department of Econometrics, \\ University of Barcelona. Avda. Diagonal, 690. 08034 Barcelona, \\ Spain. Email: Peter.Claeys@ub.edu.
}

\begin{abstract}
It is commonly believed that a fiscal expansion raises interest rates. However, these crowding out effects of deficits have been found to be small or non-existent. One explanation is that financial integration offsets interest rate differentials on globalised bond markets. This paper measures the degree of integration of government bond markets, using spatial modelling techniques to take this spillover on financial markets into account. Our main finding is that the crowding out effect on domestic interest rates is significant, but is reduced by spillover across borders. This spillover is important in major crises or in periods of coordinated policy actions. This result is generally robust to various measures of cross-country linkages. We find spillover to be much stronger among EU countries.
\end{abstract}

Key words: fiscal policy, spillover, interest rates, crowding out, spatial models.

JEL codes: C21, E43, E58, E62, F42.

\footnotetext{
* We would like to thank Anna Giribet for excellent research assistance. Peter Claeys acknowledges support by a Marie Curie Intra-European Fellowship within the 6th European Community Framework Programme.
} 


\section{INTRODUCTION}

A government running a deficit needs to turn to financial markets to place this additional public debt. Newly issued public bonds compete for financing with bonds issued by private agents. The additional demand created by the fiscal expansion pushes up interest rates, and eventually crowds out private investment. Not all economists agree that consolidating public finances would immediately reduce pressure on interest rates, however. Despite a vast literature testing crowding out, there is actually surprisingly little robust empirical support for this hypothesis. ${ }^{1}$

Interest rates are insulated from fiscal policy under two alternative conditions. The first explanation for a zero impact of deficits on aggregate macroeconomic variables is that economic agents anticipate paying down currently high deficits with higher taxes in the future. Under Ricardian Equivalence, private saving fully offsets the effect of higher public consumption (for a given level of taxation). Few economists would consider the assumptions underlying the Ricardian Equivalence null as realistic, however. More elaborate macroeconomic models that depart from the baseline Ricardian assumption easily find real economic effects of fiscal policy. There is by now also a large body of empirical evidence that clearly refutes the Ricardian hypothesis (Blanchard and Perotti, 2002).

A second explanation for the lacking crowding out effect is capital mobility. Fiscal deficits need not be financed by domestic financial resources only. Capital flows between economically integrated economies, offsetting any interest rate differentials that follow upon an increase in the domestic supply of government bonds. Under full capital mobility, domestic and foreign agents alike diversify their asset portfolio across borders. As a consequence, the budget decision of one government affects the financing conditions of all other governments on international capital markets. Domestic interest rates rise in proportion to the amount of bonds issued worldwide. For a small open economy, the crowding out effect would tend to zero. In practice, capital mobility is far from complete, as imperfect information, risk aversion and imperfect substitutability of domestic and foreign bonds introduce a home bias in portfolio decisions. As a consequence, the spillover is likely to be less than complete.

The empirical models that are used to assess the crowding out effect of fiscal policy fail to account for this spillover. A baseline test for crowding out typically regresses a domestic interest rate on some domestic fiscal indicator. Even simple extensions of this model to include the effects of fiscal policy in open economies require quite restrictive assumptions on parameterisation. Often, one simply controls for a set of additional (foreign) explanatory variables. Usually, only a particular subset of countries is examined, or identical restrictions are imposed on the transmission of fiscal 
policy across all countries. Due to the dimension of open economy models, even simple extensions quickly exhaust the available degrees of freedom. In practice, the interactions are much more complex. Spillover works out on global financial markets, and affects a large group of countries contemporaneously.

In this paper, we use spatial techniques to account for this spillover. We deliberately keep the baseline model as simple as possible to make the strongest possible case for spillover. We test a panel model that explains interest rates by fiscal variables to analyse crowding out of fiscal policy. The spatial model simply extends this baseline model for the spillover effect in all nearby foreign economies. In particular, we test the spillover of interest rates on financial markets in a spatial lag model. We then control also for spatially distributed economic linkages in a spatial error model. We test this model on a large cross section of OECD and emerging market economies over the period 1990-2005. Our main finding is that the domestic crowding effect of fiscal policy is sizeable. But the spillover on financial markets offsets the significant effects of larger deficits on interest rates. We cannot identify whether this spillover is the direct effect of financial market integration, or the by-product of the economic integration of countries. Spillover is much stronger in the midnineties when there were major crises, or policy actions were being coordinated between governments. Various measures of cross-country linkages give broadly similar results. The main findings are also robust to alternative specifications and data definitions. Finally, we find the spillover to be quite strong among EU countries.

The paper is structured as follows. In section 2, we provide a simple theoretical model for testing crowding out, and the effects of financial and economic integration. We consequently specify the spatial model for including this spillover in section 3. We then continue in section 4 by discussing the results of the baseline model of spillover of fiscal policies, and provide several robustness checks. The final section summarises the main results, and discusses some policy implications.

\section{CROWDING OUT AND SPILLOVER}

Crowding out of interest rates is typically analysed in a partial equilibrium 'loanable funds' model (Barro, 1992). This model determines the interest rate on assets from the equilibrium between the demand and supply bonds. Both the private sector and the government turn to financial markets to look for finance. Firms invest the capital raised on stock or bond markets (b) to invest in new capital stock. Additional government financing is necessary when the government runs a deficit (d). Financial intermediaries channel the demand for bonds of the private sector, both at home (f) and abroad $\left(f^{*}\right)$ sector, to match the total supply of domestic bonds $(b+d)$ :

$$
b+d=f+f^{*}
$$

\footnotetext{
${ }^{1}$ See the contrasting arguments of the European Commission (2004) and the Bush Administration (Gale and Orszag,
} 
We can illustrate all the major points of the analysis with this simple partial equilibrium model. ${ }^{2}$ Consider the case in which the government runs a higher deficit $d$. For a given demand for bonds $f+f^{*}$, the increased supply of debt will put downward pressure on the price of government bonds. Ceteris paribus, this rise in bond yields is making it more difficult for the private sector to seek finance on capital markets: government finance crowds out private bonds b on capital markets (Cebula, 1998). However, the demand for additional bonds is likely affected by the government's decision to lend. Under two alternative theoretical conditions, private sector savings fully offset the additional supply of bonds.

First, if economic agents anticipate the pay down of higher deficits they set aside savings for the higher tax burden in future periods. In the limit, domestic private saving fully offsets the effect of the higher public dissaving $d$. Under this Ricardian Equivalence hypothesis, a higher deficit d does not have an impact on aggregate macroeconomic variables at all. Many economists consider Ricardian Equivalence as a reasonable starting point for the analysis of fiscal policy. Few would endorse it as a realistic description, however. The view that private savings offset the change in public savings is not based on a firm empirical rejection since Ricardian Equivalence is not directly testable. But plenty of empirical studies have examined the alternative hypothesis that fiscal policy has any real economic effects. Recent evidence seems to converge on at least some expansionary effects on major economic variables (Blanchard and Perotti, 2002). More elaborate macroeconomic models that depart from the baseline Ricardian assumption easily find support for these real economic effects of fiscal policy. It therefore seems a safe assumption to reject the Ricardian Equivalence hypothesis.

Second, when financial markets are integrated across borders, the foreign demand for bonds $f^{*}$ can shift as well. In open economies that are economically integrated and do not impede trade or financial flows, capital flows move massively so as to offset any interest rate differential. Under these circumstances, the supply of savings is very interest rate elastic: even a small rise in $d$ is likely to trigger a large increase in $f^{*}$. The higher is capital mobility, the weaker will be the reaction of domestic interest rates to a change in the supply of domestic bonds. Under the null of full capital mobility, the rise in interest rates is simply proportional to each country's total indebtedness on the global bond market. Consequently, due to the spillover on international bond markets, the crowding out effect of deficits is only a fraction of the total rise under autarchy. In reality, this dilution is likely to be less than complete as capital mobility is partial: domestic private agents prefer to invest in domestic financial assets. As a consequence, domestic savings and investment are highly correlated (the 'Feldstein-Horioka' puzzle). This 'home bias' depends on information

2003).

2 These partial equilibrium models have been extended for intertemporal saving behaviour (Laubach, 2003; Engen and Hubbard, 2004). Dynamic macroeconomic models that include both debt non-neutrality and long term interest rates have not been developed yet, due to their complexity. 
imperfections on foreign financial markets. Neither are financial assets in different countries perfect substitutes, due to exchange rate, inflation and default risk. Due to differences in regulation across countries, risk averse agents may prefer to invest in domestic assets only. Moreover, private agents are likely to hold a larger portion of domestic public debt. Governments often prefer to place debt only domestically in order to avoid having to pay exchange rate premia, and as a commitment not to default on debt put with its own citizens. As a consequence, complete spillover is unlikely, yet it is hard to put a precise size on the spillover effect. The spillover is likely to be stronger between economies that are more closely integrated.

\section{A SPATIAL TEST FOR CROWDING OUT}

The most common test for crowding out based on the loanable funds model takes a very simple form: it basically explains domestic interest rates by domestic fiscal balances (in this case, the surplus $s_{t}$ ).

$$
i_{t}=\alpha+\beta s_{t}+\varepsilon_{t}
$$

We measure by the coefficient $\beta$ the degree of crowding out. The large number of studies that have employed various definitions of the government surplus, interest rates, econometric approaches and data sets to test (2a) can basically give support for any view. ${ }^{3}$ There are two cases in which we would not reject $\beta=0$. First, we would not find a significant crowding out effect under Ricardian Equivalence. Second, we may not be able to reject $\beta=0$ if there is capital mobility between open economies.

However, a specification like (2a) does not account for these spillover effects of financial markets. Basically, the test for crowding out only considers domestic variables, but does not account for the integration of the domestic economy with foreign economies. Existing empirical evidence on the effect of integration is little, and uses alternative ways for netting out the international linkages from the domestic crowding out effect. Due to the omission of these foreign variables that explain the spillover effect, $\beta$ would be biased downward. The reasoning is that the domestic effect of fiscal expansions will likely be larger once a proxy $X_{t}$ for the foreign demand for bonds $\mathrm{f}^{\star}$ is introduced.

$$
i_{t}=\alpha+\beta s_{t}+\phi X_{t}+\varepsilon_{t}
$$

One alternative is to condition the relation between interest rates and deficits on foreign capital inflows (Cebula and Koch, 1994). Another is to assess directly the effects of deficits on interest

\footnotetext{
${ }^{3}$ See the references in Barth et al. (1991) and the overview article by the European Commission (2004).
} 
rates abroad. In (2c), we explain interest rates in country $A$ by the crowding out by deficits in country $A$, and in addition a direct crowding out effect of deficits in country $B$.

$$
i_{A, t}=\alpha+\beta s_{A, t}+\phi s_{B, t}+\varepsilon_{t}
$$

The coefficient $\phi$ measures the size of the spillover effect. In order to estimate a specification similar to $(2 c)$, plenty of identifying restrictions are necessary that severely reduce the dimension of the open economy model. Usually, only a particular subset of countries can be examined, or identical restrictions are imposed on the transmission across all countries in a panel. Cohen and Garnier (1991) find a positive effect of US deficits on interest rates in several G7 countries. Ardagna et al. (2007) find significant crowding out effects from both domestic and foreign fiscal expansions in a panel of OECD countries. Marcellino (2002) or Giuliodori and Beetsma (2005) consider the impact of shocks to German fiscal policy on the French and Italian economy. Paesani et al. (2006) take a somewhat different approach by identifying spillover from shocks to bond markets on internationally linked capital markets. This allows them also to consider the direction of the spillover.

An alternative control that models the linkages between domestic and foreign bond markets, is to include the level of foreign interest rates in $(2 b)$.

$$
i_{A, t}=\alpha+\beta s_{A, t}+\phi i_{B, t}+\varepsilon_{t} .
$$

Quite a few papers include foreign interest rates in the analysis of crowding out. Chinn and Frankel (2007) take the German long term rate as the benchmark in their study of US fiscal policy. Caporale and Williams (2002) or Paesani et al. (2006) reduce their sample to a few G7 economies and use in turn the interest rate from the other country as a benchmark. The assumption that domestic interest rates directly depends on a single foreign benchmark rate, is rather strong. Ideally, one would like to control for the level of interest rates in various countries. Most papers construct as the benchmark interest rate an aggregate 'world' interest rate. Tanzi and Lutz (1993) argue that at the world level all spillover effects should cancel out and a significant crowding out effect of fiscal policy restored. They aggregate all domestic deficits and examine the effect on global interest rates. Ford and Laxton (1999) and De Haan and Knot (1995) do the same for OECD and EU countries respectively. Faini (2006) calculates an average euro area interest rate, and considers the fiscal effect on interest rates at home and at EMU level contemporaneously in a panel framework. In empirical applications, modelling the transmission across financial markets requires quite restrictive assumptions. Assumptions like these likely bias the direction and the strength of the spillover effect. We would expect that on financial markets, spillover is at work between different markets contemporaneously. Spillover should also be stronger between markets that are more closely connected. 
A convenient way to think of these complex linkages is with an exogenously specified matrix W that specifies the structure and intensity of the 'closeness' of different observations. The element $w_{i j}$ of $\mathrm{W}$ represents the proximity between two observations $i$ and $j$. A common specification for this weight matrix $\mathrm{W}$ is physical contiguity. Bordering regions are believed to have closer links. It is straightforward to find other W's that reflect either economic distance between countries, such as geographic distance, trade, level of economic development, cultural or institutional differences. A pattern of spatial interaction in a variable implies that the distribution of this variable across observations is not random, and therefore the co-movement of interest rates on integrated financial markets will bias the OLS estimates of (2a). With spatial spillover, parameter estimates are biased, inefficient and inconsistent (Anselin, 1988). This bias may explain the mixed findings in the empirical literature testing crowding out and spillover.

By introducing spatial lags (i.e., interest rates in neighbouring countries) we directly control for the interaction with the level of interest rates in close by units. We can rewrite (2d) more generally as a spatial autoregressive model:

$$
i_{n, t}=\alpha+\beta s_{n, t}+\rho W i_{n, t}+\varepsilon_{n, t}
$$

In specification (3a) we control the crowding out effect in country $n$ for the interaction with interest rates in all neighbouring countries (the term $W i_{n}$ ). This is a weighted measure of interest rates in the countries with which a country has 'economic links'. This spatial lag term has to be treated as an endogenous variable; equation (3a) can be estimated with ML-techniques. A positive (and significant) coefficient $\rho$ indicates spillover. We can also recast the test of significance of $\rho$ as a test for the degree of financial market integration: the larger $\rho$, the more integrated are financial markets. A significant spatial lag also reduces the bias in the estimate of the direct crowding out effect $\beta$.

Financial integration is not the only factor behind the co-movement of bond markets. Real economic integration affects macroeconomic conditions globally, and there is quite some evidence for increased synchronisation of business cycles (Doyle and Faust, 2002). Instead of a direct spillover on financial markets, the spillover could alternatively be due to a co-movement of some omitted economic variables, unrelated to financial market integration, that vary across space. There are two possible ways to account for these effects of real economic integration. First, and as in equation (2b), we proxy the economic co-movement across countries by introducing other (domestic) macroeconomic variables. Although an OLS regression of $(2 b)$ still yields unbiased estimates, inference may be misleading since the precision of the estimates is affected. Alternatively, we can introduce such spatial links in the residuals of the empirical model. Hence, 
we qualify model (2a) to include a spatial correlation structure of the error term $\varepsilon_{n}$. We then rewrite $(2 a)$ as follows:

$$
\begin{gathered}
i_{n, t}=\alpha+\beta s_{n, t}+\varepsilon_{n, t} \\
\varepsilon_{n, t}=\lambda W \varepsilon_{n, t}+v_{n, t}
\end{gathered}
$$

In this spatial error model, $v_{n, t}$ is a white noise error term. The parameter $\lambda$ in (3b) is the spatial autoregressive parameter, and reflects the spillover across countries due to economic integration.

Financial and real economic integration probably work in the same direction. Co-movements in macroeconomic factors also drive the synchronisation of financial markets. It is likely that economies with close economic (trade) links also have more tightly linked financial markets. As a consequence, the spillover effects of financial markets and economic integration may be similar, and hard to distinguish. This observational equivalence may cause the spatial lag and spatial error model to give very similar results (Kaminsky and Reinhart, 2000). ${ }^{4}$

\subsection{Specification}

We argue that we can recover significant crowding out effects of fiscal policy on interest rates if we use a spatial extension of the simple baseline model (2a) to analyse the spillover effect of fiscal policy. Hence, we depart from a model as (2a) and use spatial techniques to test and model the crowding out and spillover effect of fiscal policy.

We are interested in two effects in the spatial model. In first instance, we test the crowding out effect of domestic deficits on domestic interest rates $(\beta)$. We expect that a higher surplus (lower deficit) has a significantly negative effect on interest rates. Secondly, the spatial model allows testing for the effect of interest rates abroad. The more interest rates rise in other countries, the higher will be the domestic interest rate as well. If interest rates are very close, this suggests that global credit markets are fairly integrated. The pool of loanable funds any government draws from exceeds the available funds in the domestic credit market only. We expect that this spillover effect will be significant, and positive.

The interpretation of the spillover effect is different in the spatial lag or error model. First, in the spatial lag model, we look at the aggregate effect of all other countries' interest rates on the home country's interest rate. We interpret a significant spatial lag as evidence of a direct spillover of fiscal policy on financial markets. The spatial lag parameter $\rho$ is the slope of this reaction

\footnotetext{
${ }^{4}$ Models (3a) and (3b) can be combined in a general specification like that encompasses both effects. We do not test a general spatial model in this paper.
} 
function, and measures the degree of financial integration. Positive spatial correlation in interest rates exists if $\rho>0$, whereas there is evidence of negative spatial correlation if $\rho<0 .{ }^{5}$

The economic interpretation of the model $(3 b)$ with spatial links in the errors is slightly different. A shock to the domestic interest rate, which is not explained by fiscal policy, spills over to all other observations that are 'close'. Spatial correlation in the error term reflects a similar reaction of countries' interest rates to shocks, because of omitted variables that are spatially correlated. This indicates important economic channels of spillover, but is not related to fiscal policy per se. A positive $\lambda$ indicates positive spatial correlation of the shocks; negative $\lambda$ shows that shocks are of opposite sign.

\subsection{Data}

We estimate these two spatial models on a panel of 101 countries, for which we have annual data on interest rates and fiscal policy covering the period 1990-2005. A panel model allows combining the typical analysis of domestic crowding out in a time series model, with the spillover of interest rates in the cross section dimension. We tie both dimensions and the structure of linkages across countries, with a weight matrix $W$ that reflects geographical distance. ${ }^{6}$ Countries that are more distant are assumed to have weaker economic links. Geographic distance usually is a good proxy for economic linkages (as in the gravity model, for example). We show that our results do not depend on this specific assumption, and we check our results for different definitions of W.

Spatial panel data models have only recently been developed, and not all their properties have been examined. Our starting point is the fixed effect panel model in which subsequently spatial dependence is accounted for by including a spatially lagged term of the dependent variable. This is the expression given in (3a), including a country specific fixed effect. The standard estimation method for the fixed effect model is to eliminate the intercept term of the regression by expressing all variables as a deviation from their time average, and then using standard OLS estimators. In presence of spatial autocorrelation it is common practice to use maximum likelihood methods to estimate the demeaned equation. These spatial autoregressive models are estimated through the maximum likelihood method of estimation developed by Elhorst (2003). ${ }^{7}$

\footnotetext{
${ }^{5}$ A spatial test for financial market integration could be equally applied to other financial assets. We look at the spillover effects of government bonds on interest rates for two reasons. First, spillover on government bond markets is policy relevant. In contrast to private bond issues, fiscal policy could introduce distortions on government bond markets. I.e., there are not only pecuniary implications for other domestic or foreign issuers. Second, we can include many countries in our sample as government bonds are the most comparable asset across countries. They are usually the least risky asset and are traded on the most liquid market.

${ }^{6}$ We assign a centre to each country, and use its coordinates to calculate the distance between these centroids. We use a GIS software for these calculations.

${ }^{7}$ Consistent estimation of the individual fixed effects is not possible as $n$ grows large, due to the incidental parameter problem. Anselin and Le Gallo (2008) argue that "since spatial models rely on the asymptotics in the cross-sectional dimension to obtain consistency and asymptotic normality of estimators, this would preclude the fixed effects model from being extended with a spatial lag". However, Anselin and Le Gallo (2008) show that for consistent estimates of $\beta$,
} 
We use a nominal long term interest rate (5 to 10 years) as our dependent variable. Deficits are usually argued to affect long term interest rates. Not that many countries outside the OECD have been able to issue long term bonds, however. Most emerging market economies have financed deficits with short term bonds at a 5 years horizon at most. Similarly, fiscal data for many countries are available only over recent years. The surplus to GDP ratios all come from the IMF Government Statistics Database. As we prefer working with balanced panels over the full sample period, we consequently had to eliminate a large number of countries from the study. Due to variable data quality, we also decided to remove some outlier observations. We first run a simple pooled estimate and quitted the observation if the standard error exceeds three times the residual variance. Eventually, we have 496 observations on 31 countries over 16 years. This keeps in the sample mostly OECD countries and a few emerging market economies. ${ }^{8}$

\section{RESULTS FOR THE BASELINE MODEL}

\subsection{Spillover on financial markets: the spatial lag model}

We first estimate a simple pooled OLS regression of (2a), without any further restrictions on the spatial effects, to replicate the crowding out effect of similar studies. Table 1 reveals a very significant and quite strong crowding out effect: a rise in the surplus of $1 \%$ of GDP leads to a 109 basis points fall in the interest rate. This result continues to hold even if we impose more structure on the pooled model. A priori, we would prefer to use a fixed effects estimator. First, we include a specific group of countries. Even if we draw a number of countries from the global sample of economies, this draw is not random (Baltagi, 2001). Second, the specification (2a) is rather basic, and we do not control for other relevant determinants of interest rates. The setting of fiscal policy is rather heterogeneous across countries. As a consequence, the country-specific effect is likely correlated with the explanatory variable (the surplus). The Hausmann test indicates that a fixed effects estimator is indeed preferable. It has also been more common in this literature to use simple pooled estimates or panel fixed effects estimators (Frenkel and Chinn, 2005; Kinoshita, 2006). We report both, and find that the panel estimates of $\beta$ in the fixed or random effects model are very similar (Table 1).

Our estimate is on the high end of the range of estimates found in the literature. In the overview study of the European Commission (2004), the crowding out effect varies between about 20 and

the demeaned spatial regressions from ML estimation like in Elhorst (2003) are appropriate. One complication with this is that the variance covariance matrix of the demeaned error term is different from the usual one. Alternative approaches to the Elhorst estimation are still a topic of ongoing research.

8 The sample includes the following EU countries (Austria, Belgium, Denmark, Finland, France, Germany, Hungary, Ireland, Italy, Luxembourg, Netherlands, Portugal, Spain, the UK), some other OECD countries (Australia, Canada, Japan, Korea, New Zealand, Switzerland, Turkey, the US) and emerging markets (Colombia, Lebanon, Mexico, Pakistan, Peru, Philippines, Singapore, South Africa, Thailand). In the Appendix, we provide a detailed description of the dataset and its sources. 
100 basis points. ${ }^{9}$ For the US, the crowding out effect is usually estimated to be around 40 basis points (Canzoneri et al., 2002; Laubach, 2003; Engen and Hubbard, 2004). This result is also confirmed by VAR studies on US data, like Dai and Phillipon (2005). For EU countries, the crowding out effect is mostly smaller in magnitude (Faini, 2006). What explains the strong crowding out effect in our estimates then? Most other papers examine the crowding out effect of deficits in a single country. In contrast, panel studies, like ours, have found much stronger effects. Chinn and Frankel (2007) estimate a crowding out of interest rates between 150 and 200 basis points in a panel of the US and the largest EU countries. Similarly, Ardagna et al. (2007) use panel VAR techniques to look at the impact of deficits on interest rates in a panel of OECD countries and find a rise of 150 basis points after 10 years. De Haan and Knot (1995) reach similar conclusions for the large EU countries. Hence, the inclusion of more countries in a crosssection analysis of deficits and interest rates typically delivers stronger crowding out effects. We actually observe a similar effect in single country studies in which control variables for international capital flows are included. Cebula and Koch (1994) find that interest rates rise by more than 60 basis points after a 1\% increase in the deficit ratio, whereas capital flows reduce the effect by about 24 points. Chinn and Frankel (2007) find a stronger impact on rates, once foreign interest rates are controlled for. Tanzi and Lutz (1993) aggregate data for the G7 and find a rise in long term rates of about 150 basis points. These results suggest that a control for the spillover effect from other countries is important. Omission of linkages on international financial markets biases the findings of crowding out.

As the estimate of $\beta$ is quite likely biased, inefficient and inconsistent, we now introduce the spatial extension. In the second panel of Table 1, we present the estimates of different versions of the spatial lag model. The baseline estimate is the spatial lag model with fixed effects. We find that the crowding out effect halves in case a spatial lag is included: a deficit of $1 \%$ of GDP pushes up interest rates by 45 basis points. The spillover effect is very significant and quite large: a 1\% rise in interest rates abroad also raises domestic rates by about $0.55 \%$. The consequence is that an increase in the deficit of $1 \%$ will cause domestic interest rates to rise by 45 basis points. Consequently, the second round effect of the deficit is to push up interest rates abroad by a further $25\left(\approx 0.55 \%{ }^{*} 45 p\right.$ ) ) basis points. A government creating a deficit still faces a quite steep increase in domestic rates, but part of this increase spills over abroad.

The crowding out effect in the spatial lag model is more in line with the results of the empirical studies of single countries. This suggests that the control for the spatial links indeed corrects the initial panel estimates. As regards our findings on spillover, it is slightly harder to compare its size. Most studies simply report that the domestic crowding out effect is larger than the foreign spillover effect. Caporale and Williams (2002) find this result for the US; and Faini (2006) reports similar results for the EU countries. Ardagna et al. (2007) report that the aggregate (world) deficit affects

\footnotetext{
${ }^{9}$ See in particular the overview table in European Commission (2004) on pp. 153-55.
} 
domestic interest rates, but its impact is less relevant than that of domestic fiscal policy. In different settings, other studies have found close connections between interest rates across borders (Minford and Peel, 2007). Nonetheless, country-specific factors still play a role in explaining the deviation of domestic interest rates from the evolution in worldwide interest rates (Breedon et al., 1999). One of the main reasons is a change in the fiscal policy stance. ${ }^{10}$ Few studies report the impact that international capital flows or foreign interest rates have on domestic interest rates. Cebula and Koch (1994) find a similarly strong reduction in interest rates (24 pp) as we do.

The co-movement of interest rates may not just reflect the integration of financial markets. Economic integration makes countries susceptible to global economic developments. Trade, financial integration and similar economic structures raise the co-movement of business cycles internationally (Imbs, 2004). Economics shocks that are common to a group of countries would display a close synchronisation of economic variables. This might show up in a significant spillover effect. We introduce a time period fixed effect in the spatial panel to absorb these common shocks. We indeed find that the spillover effect is much smaller in this case, whereas the crowding out effect remains as strong (Table 1).

\subsection{Financial and real economic integration}

An alternative possibility is that the co-movements of economic variables are also spatially distributed. Another way to model these economic links is to incorporate a spatial structure in the residuals of the baseline model. The assumption is that these economic factors, except interest rates, are spatially distributed across economies. We estimate this spatial error panel model (3b).

By controlling for these spatial linkages, we pick up a significant crowding out effect. Table 2 shows that the results are very similar to those of the spatial lag model. Moreover, the spillover effect causes a $1 \%$ rise in foreign rates to raise domestic rates by 56 basis points. We can not identify whether spillover is due to either financial market integration, or the co-movement of macroeconomic variables (Kaminsky and Reinhart, 2000).

\subsection{Some control variables}

Alternatively, one may consider a correction of the baseline model (2a) with a spatial structure for the errors too naive. The factors that determine interest rates are plenty of course, and the surplus is certainly not the only determinant of (long-term) interest rates. One often stated reason for the

\footnotetext{
${ }^{10}$ Note that for other assets than government bonds, most empirical papers find similar results on the importance of spillover. Ehrmann et al. (2005) find that asset prices react more strongly to domestic shocks, but still allows for a strong spillover between the US and EU markets.
} 
ambiguous findings regarding crowding out is the contemporaneous influence of monetary policy, automatic fiscal stabilisers, interest payments on outstanding debt and any economic effects of fiscal policy itself. ${ }^{11}$ We test extensions of the spatial lag model that control for these additional regressors $X_{n, t}$, as in $(4)^{12}$

$$
i_{n, t}=\alpha+\beta s_{n, t}+\rho W i_{n, t}+\theta X_{n, t}+\varepsilon_{n, t}
$$

It is quite common in the empirical literature on crowding out to directly test the effect of public debt on (long term) interest rates, instead of using deficits. The argument is that public debt substitutes private capital, and hence it the stock of debt that has an impact on the level of interest rates (Engen and Hubbard, 2004). Moreover, the initial fiscal position of countries matters for crowding out. Fiscal policy has non-linear effects. At higher levels of debt, interest rates typically react more strongly to higher deficits (Ardagna et al., 2007). In particular, emerging market economies start paying a higher risk premium for fiscal indiscipline (Zoli, 2004).

Table 3 reports the estimates of the spatial panel lag model with fixed effects for a model augmented with public debt. Controlling for public debt gives an interesting result. The crowding out effect of the surplus becomes less strong: interest rates rise by a mere 16 basis points after a $1 \%$ rise in the deficit. Ardagna et al. (2007) find a short run effect of deficits of about 10 basis points, after controlling for debt. This effect accumulates over time to about 100 basis points, especially as the debt ratio rises. The impact of debt - albeit significant - is very small.

These results fall in a similar range as in the other studies. Single country studies find rather modest crowding out effect of higher public debt. The consensus estimate ranges between 2 and 7 basis points for the US with a variety of methodologies (Ford and Laxton, 1999; Canzoneri et al., 2002; Laubach, 2003; Engen and Hubbard, 2004). ${ }^{13}$ As for the impact of the surplus on interest rates, studies that control for links between different countries, or use a cross-section approach, find slightly stronger effects of debt. For example, the impact of debt is slightly stronger for the EU countries than in the US (Faini, 2006). Pooled estimates for a group of OECD countries show a rise of about 25 basis points after a rise in domestic debt (Ford and Laxton, 1999; Orr et al., 1995). A similar effect is found by Tanzi and Lutz (1993).

\footnotetext{
11 These effects could cause some problems of endogeneity in (2a), but these feedback effects are likely small. IV estimates are not considered in most of the literature, however. Spatial panel models that control for endogeneity of the regressors have not been developed yet.

12 In the spatial econometrics literature, the bottom-up approach for searching an adequate specification prevails. The so-called Hendry approach is not common. Florax et al. (2003) demonstrate that the specific-to-general approach slightly outperforms the Hendry approach in the case of the estimation of linear spatial models.

${ }_{13}$ The only exception is Friedman (2005), who finds that a $1 \%$ rise in the debt ratio increases interest rates by 90 basis points.
} 
Interestingly, the spillover effect is much stronger and is estimated very precisely. Three quarters of a $1 \%$ rise in the interest rates spills over to close by countries. After all crowding out and spillover effects have worked out, a $1 \%$ rise in the deficit will push up interest rates by 16 basis points at home, and by 12 basis points abroad.

Long-term interest rates are very much influenced by monetary policy in the short term. ${ }^{14}$ We control in two different ways for its effect. First, we include a short-term interest rate in the specification. At short horizons, monetary policy sets interest rates to stabilise inflation and output. Central bank decisions directly influence the financing conditions of the government (and its interest payments on outstanding debt). The insignificance of the crowding out effect confirms that the short run impact of a higher deficit may be significant in raising interest rates, but it is not very important and it is blurred by the impact of monetary policy. But once a control for short term rates is included, the spatial lag coefficient $\rho$ is negative. Such a negative spillover effect can only be explained by a substantial spatial transmission of changes in short term interest rates, which offset the co-movement of long term interest rates between neighbouring countries. Other studies also illustrate this co-movement of short term rates across borders (Minford and Peel, 2007; Ehrmann et al., 2005). Second, we include also the inflation rate. ${ }^{15}$ Higher inflation eases pressures on deficits as it erodes the real value of outstanding debt. We find that the spillover is not really affected by the spatial variations in inflation.

\subsection{Time variation in the crowding out effect}

Financial and economic integration can explain why changes in asset markets have large effects on other financial markets. Globalisation is often argued to have strengthened the spillover between economies in two different ways. On the one hand, as integration is a gradual process, we are likely to observe a change over time in the strength of spillover. On the other hand, there could be turbulence in the spillover channel due to financial or economic crises. Tranquil periods in which there is a normal degree of real and financial interdependence suddenly switch to an environment with wild co-movements during currency and financial crises (Claessens et al., 2001). Some authors argue this distinction is only apparent, and interdependence is determined by real factors that change only gradually over time (Boyer et al., 1999; Forbes and Rigobon, 2002). The results in Table 1 showed that common shocks might be more important in explaining interdependencies across countries than a genuine spillover from other economies. If interest rates are indeed driven by some common factors in any given year, then we would not expect to

\footnotetext{
${ }^{14}$ Crowding out is obscured by static specification of the relation between deficits and interest rates in (2a). The reason is that government bonds are actually traded on financial markets. As financial markets are forward looking, it is the anticipation of upcoming deficits, rather than the current fiscal balance, that results in higher long term rates instantly. A few studies include expectations about the deficit or ratings, and directly analyse the effect of these budget projections on expected interest rates (Laubach, 2003). These data are available for a limited sample only. Papers that look into the effect of deficit announcements by the government, or analyse the effect of deficits on risk premia usually ignore the spillover effects of fiscal policy, with the exception of Kitchen (1996).
} 
see a spillover effect in a year-by-year estimation of the spatial lag model. All interdependencies would be absorbed by the constant term in this cross-section model. Note that if spatial links are predominantly determined by contagious crises across emerging economies, the annual frequency of fiscal data may not pick up the high frequency movements on financial markets due to sudden fiscal crises.

We turn again to the standard spatial lag model for explaining the variation in interest rates by fiscal variables but estimate it at a cross-sectional level for each year. Note that the efficiency of these cross-section estimates is smaller than in the panel case. Figure 1 plots the coefficients of an ML estimation of the baseline regression over the sample 1990 to 2005.

We have three major results. First, there is a crowding out effect of fiscal policy on interest rates: a fall in the surplus (higher deficit) raises interest rates. Second, the spillover effect is not particularly stable. The spatial lag coefficient varies in a rather large band between 0 and 40 basis points since the mid nineties, but there are some strong drops in 1994 and 2004. Finally, both effects vary over time. We can distinguish three different episodes. In the first half of the nineties, fiscal policy has hardly got any crowding out effects. Foreign interest rates tend to go in the opposite direction of domestic rates. In a second period, which goes from the mid nineties to the year 2000 , crowding out is significant and large. At the same time, spillover becomes stronger as well. Starting in 1999, crowding out and spillover both become less pronounced. There is a gradual decline in the estimated coefficients $\beta$ and $\rho$. These results are also corroborated by the findings of a cross-section estimation of the spatial error model.

These results teach us some important lessons. First, if we compare these findings with our panel estimates with time period effects, we cannot clearly attribute the smaller spillover effect to common shocks only. There is an important change in the crowding out effect as well.

It is not surprising that spatial links are increasingly important in explaining the transmission of interest rates across borders. Increasing globalisation is believed to have spurred capital mobility and increased trade flows. Linkages on international markets have certainly become much stronger than they were a decade ago. Moreover, the nineties have seen several large crises that have spread to other countries. The 1994 Tequila crisis in Mexico was the first big 'fiscal crash'. The Asian Flu that started in 1997 in Thailand set off a series of problems in the Asian Tigers, but spread globally. Russia defaulted in 1998 after Brazil had devalued the real a few months before. Argentina defaulted in 2001 and Turkey experienced fiscal and monetary trouble in the same year. Since then, no major 'emerging market' crisis has occurred. We find a break in spillover: there are no significant spatial links since 2001. In contrast to the nineties, domestic crises have had much less impact abroad in recent years. There could be two reasons for this. First, domestic crises are less serious now than they were in the nineties. Second, even though financial and economic

${ }^{15}$ Data on inflation expectations are not available for all countries in the sample. 
integration are progressing, contagion is now much weaker. Other studies have also found that spillover has become much weaker in recent years. Forbes and Chinn (2004) also find evidence of stronger links over the period 1996-2000. Didier et al. (2006) show that the co-movement of emerging market bond spreads and returns have been declining since 2000. Mauro et al. (2006) present similar results.

The reasons for the changes in the crowding out effect are unclear. Large international crises can explain the large crowding out effect in the mid nineties. In fact, some - but not all - of the emerging market crises started with domestic fiscal problems. High and rapidly growing public debt cast current monetary policy strategies into doubt, and meant high interest rates to prevent capital from fleeing the country. This is only a partial explanation, however. For lack of data, we have not been able to include many emerging markets in the sample. And even if these economies in crisis had a global impact, the mere size of their budget problems is probably too small to affect interest rates in industrialised economies. Instead, fiscal policy in both the US and the EU was much more focused on debt consolidation in the nineties. The Clinton Administration governed a $10 \%$ reduction in public debt in the span of five years, in part helped by the strongly booming economy. In addition, EU countries decided on a common fiscal retrenchment and a strict monetary policy stance to prepare for EMU. EU countries had to abide by the rules of the Stability and Growth Pact in order to qualify for the eurozone. After this joint consolidation effort, budget discipline has become less tight. It should not come as a surprise that after the entry in the EMU in 1999, crowding out is much smaller.

\section{SOME ROBUSTNESS CHECKS}

\subsection{Global or local linkages}

We immediately pick up on the previous explanation for the change in the crowding out effect. Fiscal consolidation in the EU countries might indeed be responsible for the large crowding out effect in the mid nineties. There are additional reasons to expect a stronger spillover effect between EU member states over time. Strong interlinkages are the consequence of ongoing economic and financial integration, and this must have strengthened the spillover of economic policies between these countries. In addition, for those EU countries participating in monetary union, spillover may even be stronger. A common monetary policy has spurred financial integration and probably also trade links. If different governments borrow in the same currency, as in a monetary union, free riding makes each government disregard its own intertemporal budget constraint (Chari and Kehoe, 2007). A variety of reasons may be invoked for the lack of credibility of the no bailout clause that prevents other governments (or the central bank) from rescuing the insolvent government. The offsetting interest rate effects do not need to materialise then, as 
default premia are spread out over all members of the union. ${ }^{16}$ In the absence of agreements specifying the fiscal relations between governments, the crowding out effect depends - ceteris paribus - on the aggregate fiscal policy stance of all member states.

Could spatial links be stronger between particular groups of countries, or are capital markets truly global? We run the same baseline model for some subsamples of countries. We are particularly interested in the subgroup of EU countries. The results of the spatial tests must be taken with some caution since we include only 13 EU countries. The properties of spatial panel tests are instead asymptotically valid.

Table 4 summarises the results of the different specifications of the spatial panel. Crowding out is much less significant for an EU country. In contrast to the 'global' sample, a 1\% deficit raises interest rates by only 10 basis points. Notwithstanding, the total effect on interest rates is much larger due to the spillover effect. Nearly $90 \%$ of an interest rate rise is transmitted to other EU countries. A $1 \%$ deficit raising domestic rates by 10 points will - in a second step - cause a rise in foreign rates of about 9 basis points. Hence, deficits will raise interest rates by nearly the same amount at home as in another EU country. As before, the panel with fixed or random effects gives very similar results. There is again some evidence that common shocks are driving interest rates. The results of the spatial panel model are somehow altered when accounting for time period fixed effects. The spillover effect is much weaker, and the crowding out effect is completely absent. As regards the source of the spillover, there is not much evidence to identify the role of financial or economic integration in the transmission of interest rates across EU countries. The estimates of the spatial error model show an important spillover effect, but no crowding out.

Most studies have examined spillover between OECD countries. We look at the industrialised economies, but exclude the most recently acceded member states. Our baseline results for the global sample are not much affected: crowding out effects are significant and spatial links are rather large. The estimates are of the same order as for the global sample.

\subsection{Different weight matrices}

For all previous results, we have used a measure of geographical distance as a proxy for cross country economic linkages. We check if the results are robust to other definitions of the weight matrix $\mathrm{W}$, and focus on the spatial panel lag model with fixed effects. ${ }^{17}$ We first try out some different measures of distance. We alternatively measure the (inverted) distance between countries as the distance between capital cities, or the great circle distance between country

\footnotetext{
${ }^{16}$ Yardstick comparisons across governments may partially undo this spillover, if the accumulation of debt by one government increases the relative creditworthiness of comparable governments.

17 This result is robust for the other panel models.
} 
centroids. ${ }^{18}$ Table 5 shows that the point estimates are very similar, and so is the significance of both effects. A more common choice of the weighting matrix in spatial studies is physical contiguity. Countries that share a common border are believed to transmit effects to their direct neighbours, but no effect at all to far-away countries. Under this type of transmission mechanism, crowding out is only marginally stronger, but the spatial effect is negative. The reason is that border links are an awkward choice, as there are plenty of missing observations in our sample. Only a few European countries share a common border, but most other economies are isolated from each other (i.e., there are many zeros in the weighting matrix). This downplays the importance of spatial transmission.

Physical distance is at best a proxy for the integration of countries' financial markets, but still gives little economic content to 'being close'. Our estimates of the spillover effect could be quite conservative as a consequence. We experiment with some more 'economic' weight matrices. It is often argued that trade is a major channel for economic transmission across countries. We therefore use different possible weight matrices incorporating bilateral exports and imports. We scale total exports from country $i$ to country $j$ by total exports of country $i{ }^{19}$ Similarly, for imports of country $j$ we scale by total imports of country $\mathrm{j} .{ }^{20}$ We also weigh by total trade, summing bilateral exports and imports, and dividing by total trade of the country. As a consequence, these weight matrices are asymmetric: the strength of the transmission depends on the size and importance of each country. For example, the US may trade a lot with Colombia, yet the importance of this trade volume for the US economy is tiny. In contrast, for Colombia, US trade is much more important. We would expect the spillover from the US to Colombia to be much stronger than vice versa. This weight matrix better reflects the strength of transmission from large to small economies. Surprisingly, none of the results of the baseline model is altered very much. The crowding out effect is as large as before, and so is the spatial effect. Keleijan et al. (2006) similarly find little differences between the use of trade or distance matrices in their analysis of financial market spillover. This result confirms that distance is a good proxy for trade and economic relations in a gravity model.

One might argue that trade is endogenous to the strength of the economic links. We choose an alternative weight matrix that has a dummy if two countries are in a free trade agreement. This results in a slightly stronger crowding out effect, and weaker spatial links. However, the results could be biased. There are a few countries only that do not have some kind of bilateral trade agreement in our sample. As a consequence, the importance of spatial links is probably understated.

\footnotetext{
${ }_{18}^{18}$ A great circle is the shortest path between two points along the surface of a sphere.

${ }^{19}$ All data are in USD, trade data are FOB or CIF. Spatial panel models cannot handle time varying weight matrices. We arbitrarily fix exports and imports at a base year in the mid-of-sample (1998). Two countries are 'close' if they have strong bilateral trade (relative to the other trading partners). In contrast to the literature on contagion, we do not use the competition for export shares on third markets (Forbes and Chinn, 2004).

${ }^{20}$ The two numbers do not match for statistical reasons. This is known as the 'missing trade' problem.
} 
The panel model provides an average effect of fiscal policy on interest rates, while arguably these crowding out and spillover effects may differ across countries. Changes in fiscal policy in the large industrialised economies are likely to have a larger effect on smaller economies. The transmission of economic events is likely to run in one direction. For example, measured by great circle distance, Germany is equally distant from France and Hungary. The impact of changes in the German economy is likely to be large for both countries. Yet, the inverse impact of the French economy on Germany is almost certainly much larger than that of the Hungarian economy. We control for the direction of spillover and the importance of transmission between economies by multiplying country size (GDP in USD PPP terms) by physical distance. Nonetheless, the results do not change much if we use this asymmetric weight matrix.

Both industrialised and emerging market economies are increasingly open to financial markets. Financial integration between industrialised economies is gradually proceeding with economic integration. Instead, emerging market economies could be subject to contagious crises that spread from a crisis in another emerging market, but are unrelated to the economic fundamentals (and in particular the fiscal position) of the country itself. Economic crises may spread faster between emerging markets that are more exposed on financial markets, have similar macroeconomic characteristics or are prone to information asymmetries that trigger sunspot crises. As a final robustness check, we try to model these various channels of contagion. We capture the heterogeneity between industrialised and emerging economies by the difference in economic development. We use a weight matrix in which spatial links are stronger if the difference of (log) per capita income (in PPP USD) is smaller. We do not find significant differences in the crowding out effect, and the spatial effects remain as strong as with the other weight matrices.

Our weight matrix is a rather rough attempt to distinguish links between industrialised and emerging market economies. We have not attempted to model these channels of contagion with alternative definitions of the weight matrix. ${ }^{21}$ It has been argued that these alternative channels may be less important than the classical transmission channels, such as trade (see the findings of Gerlach and Smets, 1995). Eichengreen and Rose (2001) and Forbes and Chinn (2004) also find that real and financial linkages are predominantly determined by 'real' trade integration. Kaminsky and Reinhart (2000) argue that trade or financial links are hard to distinguish, and hence often both specifications give very similar results.

\subsection{Alternative data definitions}

\footnotetext{
${ }^{21}$ Alternative definitions could be: interest rate spread, stock market index, exchange rate regime, real exchange rate, competition for bank lending, or international reserves. Data on these other channels are unfortunately not completely available for all countries in our sample.
} 
Fiscal policy is argued to affect interest rates at long horizons. This can be tested in most industrialised economies that are able to issue long term bonds at a horizon of ten or more years. Not that many countries outside the OECD have been able to issue long term bonds, however. Most developing economies can only get finance on capital markets at short horizons, and have financed deficits with short term bonds at a 5 years horizon at most. We add to the sample those countries that issue government bonds at a horizon shorter than five years, and also use a shortto medium term interest rate (of 1 to 5 years) as our dependent variable for the countries in the initial sample. Table 6 gives the results of the spatial panel lag model with fixed effects. For the baseline model, the results barely change. If we augment the model with some additional control variables, the results still do not change very much. This is surprising, given that with a few exceptions (Barth et al., 1984), the literature usually does not find effects of deficits on short term rates (Cebula, 2000). We also add several control variables to this specification, and confirm the results of section 4.3. The crowding out effect is weaker when we add public debt, but the spillover effect becomes much stronger. If we add inflation, only the spillover effect is important. When data are available, we also add as a control the long term rate. In this case, both the crowding out and spillover effect disappear.

The level of interest rates is determined by many other factors than fiscal policy. As argued in section 4.3, it is the level of public debt that determines crowding out. The addition of new stock of public debt should instead put additional pressure on the change in interest rates. Hence, instead of using the level of interest rates as the dependent variable, one should use the first difference instead. Table 6 shows that this does not affect the estimates of the crowding out effect, nor of the spillover. The addition of control variables does not change our conclusions.

Finally, some other studies have used the yield to filter out any of the short term effects of fiscal or monetary policy, and analyse the impact of expected deficits on interest rates. The argument is that higher future deficits translate into higher interest rates in the future, and hence, a steepening of the yield curve. By using the yield as the dependent variable, there is no need to model the factors that drive the level of interest rates. We subtract from the long term interest rate the short term rate, and use this yield as a dependent variable. The estimation of the baseline model does not show very different results, even if we add the usual control variables.

\section{CONCLUSIONS}

There is much discussion about the effect of fiscal expansions on interest rates. This variety in opinion is due to the little robust empirical endorsement for crowding out. A lack of response of interest rates can be justified under two different theoretical conditions. First, under Ricardian Equivalence, deficits do not affect macroeconomic variables as economic agents anticipate the paydown of higher deficits with future taxes. Second, capital flows between economically 
integrated economies offset any interest rate differentials that follow upon an increase in the supply of government bonds. Fiscal deficits are not necessarily financed by domestic financial resources only. Financing conditions of governments depend on international capital markets.

Theoretical models of open economies displaying non-neutrality of debt and including long term interest rates have not been developed. With little theoretical guidance, the robustness of the empirical tests is important. In this paper, we concentrate on modelling the crowding out effect of deficits on interest rates in open economies. We extend a simple empirical model for testing crowding out and test it with spatial techniques. Spatial models impose few restrictions on the spillover, as the contemporaneous interactions on many capital markets is taken into account.

Our main finding is that there are significant and robust effects of larger deficits on interest rates. Spillover mitigates this effect. It is not obvious that this spillover is related to fiscal policy directly, as both financial and economic integration may drive the spillover. Spillover is much stronger in the mid-nineties when there are major crises, or policy actions have been coordinated between governments. We find the spillover effect to be particularly strong among EU countries.

Our results have some implications for fiscal policy. The argument for coordination of fiscal policy is perhaps not convincing in case the spillover occurs on capital markets. After all, the mitigating effect of financial markets is a purely pecuniary externality and does not really require international coordination. The allocation of savings to the public or private sector, whether at home or abroad, is efficient. Nonetheless, in case spillover is related to contagion on financial markets (in the case of emerging economies) or to monetary union (in the case of EMU) this distorts capital markets. Some institutional correction mechanisms might then be necessary. Given that crowding out, and spillover, is quite strong in the EMU, this justifies fiscal rules as in the Stability and Growth Pact. 


\section{REFERENCES}

ANSELIN, L., 1988, Lagrange Multiplier test diagnostics for spatial dependence and spatial heterogeneity, Geographical Analysis, 20, 1-17.

ANSELIN, L. and LE GALLO, J. (2008) Spatial Panel Econometrics, Chapter 18.

ARDAGNA S., CASELLI F. and LANE T., 2007, Fiscal discipline and the cost of public debt service: some estimates for OECD countries, Journal of Macroeconomics, 7(1).

BALTAGI , 2001, Econometric Analysis of Panel Data, John Wiley and Sons, Chichester, 2nd edition.

BARRO R., 1992, World interest rates and investment, Scandinavian Journal of Economics, 94(2), 323-42.

BARTH J., IDEN G. and RUSSEK F., 1984, Do federal deficits really matter?, Contemporary Policy Issues, 3(1), 79-95.

BARTH J., IDEN G., RUSSEK F. and WOHAR M., 1991, The effects of federal budget deficits on interest rates and the composition of domestic output, in: PENNER R. (ed.), The Great Fiscal Experiment, Washington: Urban Institute Press, 69-141.

BLANCHARD O. and PEROTTI R., 2002, An empirical characterisation of the dynamic effects of changes in government spending and taxes on output, Quarterly Journal of Economics, 117(4), 1329-1368.

BOYER B., GIBSON M. and LORETAN M., 1999, Pitfalls in tests for changes in correlations, Federal Reserve Board, International Finance Division, working paper 597.

CANZONERI, MATTHEW B., CUMBY R. and DIBA B., 2002, Should the ECB and the Federal Reserve be concerned about fiscal policy?, in: Rethinking Stabilization Policy, Kansas City: Federal Reserve Bank of Kansas City, 333-389.

CAPORALE G. and WILLIAMS G., 2002, Long-term nominal interest rates and domestic fundamentals, Review of Financial Economics, 11, 119-130.

CEBULA R., 1998, An empirical analysis of the impact of federal budget deficits on long-term nominal interest rate yields: using alternative expected inflation measures, Review of Financial Economics, 7(1), 55-64.

CEBULA R., 2000, Impact of budget deficits on ex post real long-term interest rates, Applied Economics Letters, 7(3), 177-179.

CEBULA R. and KOCH J., 1994, Federal budget deficits, interest rates, and international capital flows: a further note, Quarterly Review of Economics and Finance, 34(1), 117-120.

CEBULA R.J., 2000, Impact of budget deficits on real long-term interest ex post rates, Applied Economics Letters, 7(3), 177-179.

CHARI V. and KEHOE P., 2007, On the need for fiscal constraints in a monetary union, Journal of Monetary Economics, 54(8), 2399-2408.

CHINN M. and FRANKEL J., 2007, Debt and interest rates: the US and the Euro Area, Economics Discussion Paper 11. 
CLAESSENS S., DORNBUSCH R. and PARK Y., 2001, International financial contagion: how it spreads and how it can be stopped, in: CLAESSENS S. and FORBES K., International Financial Contagion. Boston, Kluwer Academic Publishers, 3-18.

COHEN D. and GARNIER O., 1991, The impact of forecasts of budget deficits on interest rates in the US and other G7 Countries, mimeo, Board of Governors of the Federal Reserve System.

DAI Q. and PHILIPPON T, 2005, Fiscal policy and the term structure of interest rates, NBER working paper 11574.

DIDIER T., MAURO P. and SCHMUKLER S., 2006, Vanishing financial contagion, IMF Policy Discussion Paper 1.

DOYLE B., and FAUST J., 2002, An investigation of co-movement among the growth rates of the G7 countries, Federal Reserve Bulletin, 88, 427-437.

EHRMANN M., FRATZSCHER M. and RIGOBON R., 2005, Stocks, bonds, money markets and exchange rates: measuring international financial transmission, NBER working paper 11166.

EICHENGREEN B. and ROSE A., 2001, Staying afloat when the wind shifts: external factors and emerging-market banking crises, in: CALVO G. et al., Money, Capital Mobility, and Trade: Cambridge: MIT Press, 171-205.

ELHORST J., 2003, Specification and estimation of spatial panel data models, International Regional Science Review, 26(3), 244-268.

ENGEN E. and HUBBARD R., 2004, Federal government debt and interest rates, NBER Macroeconomics Annual, Cambridge, Massachusetts: NBER, 83-138.

EUROPEAN COMMISSION, 2004, Public Finances in EMU, European Economy, DG for Economic and Financial Affairs, 3.

FAINI R., 2006, Fiscal policy and interest rates in Europe, Economic Policy, 21(47), 443-489.

FLORAX R., FOLMER H. and REY S., 2003, Specification searches in spatial econometrics: The relevance of Hendry's methodology, Regional Science and Urban Economics, 33, 557-579.

FORBES K. and RIGOBON R., 2002, No contagion, only interdependence: measuring stock market co-movements, Journal of Finance, 57, 2223-2261.

FORBES K., CHINN J. and MENZIE D., 2004, A decomposition of global linkages in financial markets over time, Review of Economics and Statistics, 86(3), 705-722.

FORD R. and LAXTON D., 1999, World public debt and real interest rates, Oxford Review of Economic Policy, 15(2), 77-94.

BREEDON F., HENRY B. and WILLIAMS G., 1999, Long-term real interest rates: evidence on the global capital market, Oxford Review of Economic Policy, 15(2), 128-142.

FRIEDMAN B., 2005, Deficit and debt in the short and long run, NBER working paper 11630.

GALE W. and ORSZAG P., 2003, The economic effects of long-term fiscal discipline, UrbanBrookings Tax Policy Center Discussion Paper 60.

GERLACH S. and SMETS F., 1995, Contagious speculative attacks, European Journal of Political Economy, 11(1), 45-63. 
GIULIODORI M. and BEETSMA R., 2005, What are the spillover from fiscal shocks in Europe? An empirical analysis, De Economist, 153(2), 167-197.

IMBS J., 2004, Trade, finance, specialization, and synchronization, Review of Economics and Statistics, 86(3), 723-34.

KAMINSKY G. and REINHART C., 2000, On crises, contagion and confusion, Journal of International Economics, 51, 145-168.

KELEJIAN H., TAVLAS G. and HONDROYIANNIS G., 2006, A spatial modelling approach to contagion among emerging economies, Open Economies Review, 17(4-5), 423-441.

KINOSHITA N., 2006, Government debt and long-term interest rates, IMF working paper 63.

KITCHEN J., 1996, Domestic and international financial market responses to federal deficit announcements, Journal of International Money and Finance, 15(2), 239-254.

KNOT K. and DE HAAN J., 1995, Fiscal policy and interest rates in the European Community, European Journal of Political Economy, 11(1), 171-187.

LAUBACH T., 2003, New evidence on the interest rate effects of budget deficits and debt, Board of Governors of the Federal Reserve System, working paper 12.

MARCELLINO M., 2002, Some stylised facts on non-systematic fiscal policy in the Euro-area, CEPR discussion paper 3635.

MAURO P. NATHAN S. and YISHAY Y., 2006, Emerging markets and financial globalization: sovereign bond spreads in 1870-1913 and today, Oxford University Press.

MINFORD P. and PEEL D., 2007, On the equality of real interest rates across borders in integrated capital markets, Open Economics Review, 18(1), 119-125.

ORR A, EDEY M., KENNEDY M., 1995, Real long-term interest rates: the evidence form pooledtime-series, OECD Economic Studies, 25, 75-107.

PAESANI P., STRAUCH R., and KREMER, M., 2006, Public debt and long-term interest rates: the case of Germany, Italy and the USA, ECB working paper 656.

TANZI V. and LUTZ M., 1993, Interest rates and government debt: are the linkages global rather than national?, in: VERBON H. and VAN WINDEN F., The Political Economy of Government Debt, Amsterdam: Elsevier Science, 233-253.

ZOLI E., 2004, How does fiscal policy affect monetary policy in emerging market countries?, BIS working papers 174 . 


\section{TABLES}

Table 1. Baseline model, pooled and panel estimates; and spatial panel lag model (Wmatrix $=$ distance).

\begin{tabular}{|c|c|c|c|c|c|c|}
\hline & & $\beta$ & t-stat & $\rho$ & t-stat & \\
\hline & pooled & -1.09 & -5.22 & - & - & - \\
\hline \multirow{3}{*}{ panel } & panel, fixed effects & -1.16 & -5.30 & - & - & \\
\hline & panel, random effects & -1.06 & -5.20 & - & - & \\
\hline & Hausmann test statistic & $\begin{array}{l}15.05 \\
(0.00)\end{array}$ & & & & \\
\hline \multirow{3}{*}{ spatial lag } & panel, fixed effects & -0.45 & -4.54 & 0.55 & 8.09 & - \\
\hline & panel, random effects & -0.46 & 2.02 & 0.51 & 0.00 & \\
\hline & $\begin{array}{l}\text { panel, spatial + tıme } \\
\text { period fixed effects }\end{array}$ & -0.43 & -4.09 & -0.05 & -0.37 & \\
\hline
\end{tabular}

Table 2. Baseline model, spatial panel error model (W-matrix=distance).

\begin{tabular}{lcccc}
\hline \hline & $\beta$ & t-stat & $\lambda$ & t-stat \\
panel, fixed effects & -0.44 & -4.17 & 0.56 & 8.42 \\
panel, random effects & -0.48 & -4.26 & 0.52 & 5.28 \\
panel, spatial + time period fixed effects & -0.43 & -4.10 & -0.06 & -0.43 \\
\hline \hline
\end{tabular}

Table 3. Augmented model, spatial panel lag model, spatial fixed effects, specifications (Wmatrix=distance): $i_{n, t}=\alpha+\beta s_{n, t}+\rho W i_{n, t}+\theta X_{n, t}+\varepsilon_{n, t}$

$X_{t}=\left\{\begin{array}{l|cccccc}\hline \hline & \beta & \mathrm{t}-\text { stat } & \rho & \mathrm{t} \text {-stat } & \theta & \mathrm{t} \text {-stat } \\ \text { baseline } & -0.45 & -4.54 & 0.55 & 8.09 & - & - \\ \text { debt } & -0.16 & -2.94 & 0.73 & 17.28 & -0.00 & 2.07 \\ \text { short term interest rate } & 0.00 & 0.00 & -0.53 & -2.98 & 0.04 & 2.78 \\ \text { inflation } & 0.01 & 0.29 & 0.34 & 3.37 & 0.01 & 0.28 \\ \hline\end{array}\right.$


Table 4. Baseline model, spatial panel lag, country groups (W-matrix=distance).

\begin{tabular}{|c|c|c|c|c|}
\hline EU15 & \multicolumn{3}{|c|}{ (number of observations $=208$ ) } & \multirow[b]{2}{*}{ t-stat } \\
\hline spatial lag & $\beta$ & t-stat & $\rho$ & \\
\hline panel, fixed effects & -0.10 & -2.54 & 0.86 & 36.46 \\
\hline panel, random effects & -0.11 & 2.02 & 0.86 & 33.37 \\
\hline panel, spatial + time period fixed effects & -0.01 & -0.09 & 0.29 & 2.56 \\
\hline spatial error & $\beta$ & t-stat & $\lambda$ & t-stat \\
\hline panel, fixed effects & -0.03 & -0.52 & 0.88 & 43.35 \\
\hline panel, random effects & -0.21 & -3.77 & 0.81 & 22.13 \\
\hline panel, spatial + time period fixed effects & 0.00 & -0.09 & 0.26 & 2.31 \\
\hline$O E C D$ & \multicolumn{3}{|c|}{ (number of observations $=352$ ) } & \\
\hline spatial lag & $\beta$ & t-stat & $\rho$ & t-stat \\
\hline panel, fixed effects & -0.45 & -4.54 & 0.55 & 8.09 \\
\hline panel, random effects & -0.46 & 1.54 & 0.53 & 6.69 \\
\hline panel, spatial + time period fixed effects & -0.43 & -4.09 & -0.05 & -0.37 \\
\hline spatial error & $\beta$ & t-stat & $\lambda$ & t-stat \\
\hline panel, fixed effects & -0.44 & -4.17 & 0.56 & 8.42 \\
\hline panel, random effects & -0.48 & -4.26 & 0.52 & 5.28 \\
\hline panel, spatial + time period fixed effects & -0.43 & -4.10 & -0.06 & -0.43 \\
\hline
\end{tabular}

Table 5. Baseline model, spatial panel lag model, various weight matrices.

\begin{tabular}{|c|c|c|c|c|}
\hline & $\beta$ & t-stat & $\rho$ & t-stat \\
\hline & \multicolumn{4}{|c|}{ panel, fixed effects } \\
\hline inverted distance ${ }^{\text {a) }}$ & -0.45 & -4.54 & 0.55 & 8.09 \\
\hline inverted distance ${ }^{\text {b) }}$ & -0.48 & -4.81 & 0.40 & 5.72 \\
\hline circle distance & -0.45 & -4.57 & 0.53 & 7.59 \\
\hline border & -0.64 & -5.62 & -0.24 & -3.86 \\
\hline country size*distance & -0.45 & -4.54 & 0.55 & 8.09 \\
\hline exports & -0.45 & -4.55 & 0.55 & 9.37 \\
\hline imports & -0.45 & -4.57 & 0.55 & 9.09 \\
\hline trade & -0.45 & -4.55 & 0.54 & 9.11 \\
\hline free trade area & -0.54 & -5.16 & 0.20 & 1.96 \\
\hline \multirow[t]{2}{*}{ GDP per capita } & -0.48 & -4.76 & 0.41 & 5.83 \\
\hline & \multicolumn{4}{|c|}{ panel, random effects } \\
\hline inverted distance $^{\text {a) }}$ & -0.46 & 2.02 & 0.51 & 0.00 \\
\hline inverted distance ${ }^{\text {b) }}$ & -0.49 & 2.09 & 0.37 & 5.15 \\
\hline circle distance & -0.47 & 1.63 & 0.50 & 6.62 \\
\hline border & -0.53 & 2.75 & 0.19 & 0.00 \\
\hline country size ${ }^{*}$ distance & -0.46 & 2.05 & 0.53 & 0.00 \\
\hline exports & -0.49 & 2.30 & 0.40 & 5.15 \\
\hline imports & -0.48 & 2.22 & 0.43 & 0.00 \\
\hline trade & -0.48 & 2.24 & 0.44 & 0.00 \\
\hline free trade area & -0.55 & 2.30 & 0.18 & 3.52 \\
\hline \multirow[t]{2}{*}{ GDP per capita } & -0.49 & 1.96 & 0.37 & 0.00 \\
\hline & \multicolumn{4}{|c|}{ panel, spatial and time period fixed effects } \\
\hline inverted distance $^{\text {a) }}$ & -0.43 & -4.09 & -0.05 & -0.37 \\
\hline inverted distance $^{\text {b) }}$ & -0.43 & -4.11 & 0.04 & 0.48 \\
\hline circle distance & -0.43 & -4.09 & -0.05 & -0.39 \\
\hline border & -0.44 & -4.09 & -0.24 & -3.82 \\
\hline country size ${ }^{*}$ distance & -0.43 & -4.09 & -0.05 & -0.37 \\
\hline exports & -0.43 & -4.06 & 0.10 & 1.12 \\
\hline imports & -0.43 & -4.07 & 0.06 & 0.58 \\
\hline trade & -0.43 & -4.06 & 0.08 & 0.83 \\
\hline free trade area & -0.41 & -3.94 & -0.11 & -0.88 \\
\hline GDP per capita & -0.43 & -4.10 & 0.01 & 0.14 \\
\hline
\end{tabular}

Notes: (a) distance between centroids of the country coordinates; (b) distance between capital cities. 
Table 6. Augmented model, spatial panel lag model, spatial fixed effects, specifications (Wmatrix=distance): $i_{n, t}=\alpha+\beta s_{n, t}+\rho W i_{-n, t}+\theta X_{n, t}+\varepsilon_{n, t}$

\begin{tabular}{|c|c|c|c|c|c|}
\hline \multirow[t]{2}{*}{ dependent } & short term interest rate & $\beta$ & t-stat & $\rho$ & t-stat \\
\hline & baseline & -0.52 & -2.66 & 0.48 & 6.39 \\
\hline \multirow{3}{*}{$X_{t}=$} & debt & -0.09 & -2.03 & 0.77 & 21.39 \\
\hline & long term interest rate & 0.03 & 0.16 & 0.14 & 1.23 \\
\hline & inflation & 0.01 & 0.24 & 0.45 & 5.65 \\
\hline \multirow[t]{2}{*}{ dependent } & $\begin{array}{l}\Delta \text { long term interest } \\
\text { rate }\end{array}$ & $\beta$ & t-stat & $\rho$ & t-stat \\
\hline & baseline & -0.61 & -2.72 & 0.44 & 5.44 \\
\hline \multirow{3}{*}{$X_{t}=\{$} & debt & -0.09 & -1.91 & 0.76 & 19.54 \\
\hline & short term interest rate & 0.00 & 0.00 & 0.00 & -0.01 \\
\hline & inflation & 0.01 & 0.24 & 0.42 & 5.09 \\
\hline \multirow[t]{2}{*}{ dependent } & $\Delta$ interest rate & $\beta$ & t-stat & $\rho$ & t-stat \\
\hline & baseline & -0.56 & -2.03 & 0.29 & 3.05 \\
\hline \multirow{3}{*}{$X_{t}=\{$} & debt & -0.09 & -2.03 & 0.77 & 21.30 \\
\hline & long term interest rate & 0.14 & 0.65 & 0.21 & 1.94 \\
\hline & inflation & 0.05 & 1.62 & 0.44 & 5.77 \\
\hline \multirow[t]{2}{*}{ dependent } & yield & $\beta$ & t-stat & $\rho$ & t-stat \\
\hline & baseline & -0.52 & -2.66 & 0.48 & 6.39 \\
\hline \multirow{2}{*}{$X_{t}=$} & debt & -0.12 & -2.94 & 0.73 & 17.95 \\
\hline & inflation & 0.03 & 1.03 & 0.35 & 3.84 \\
\hline
\end{tabular}




\section{FIGURES}

Figure 1. Baseline model, spatial model estimates ( $W=$ distance matrix).

(a) spatial lag model

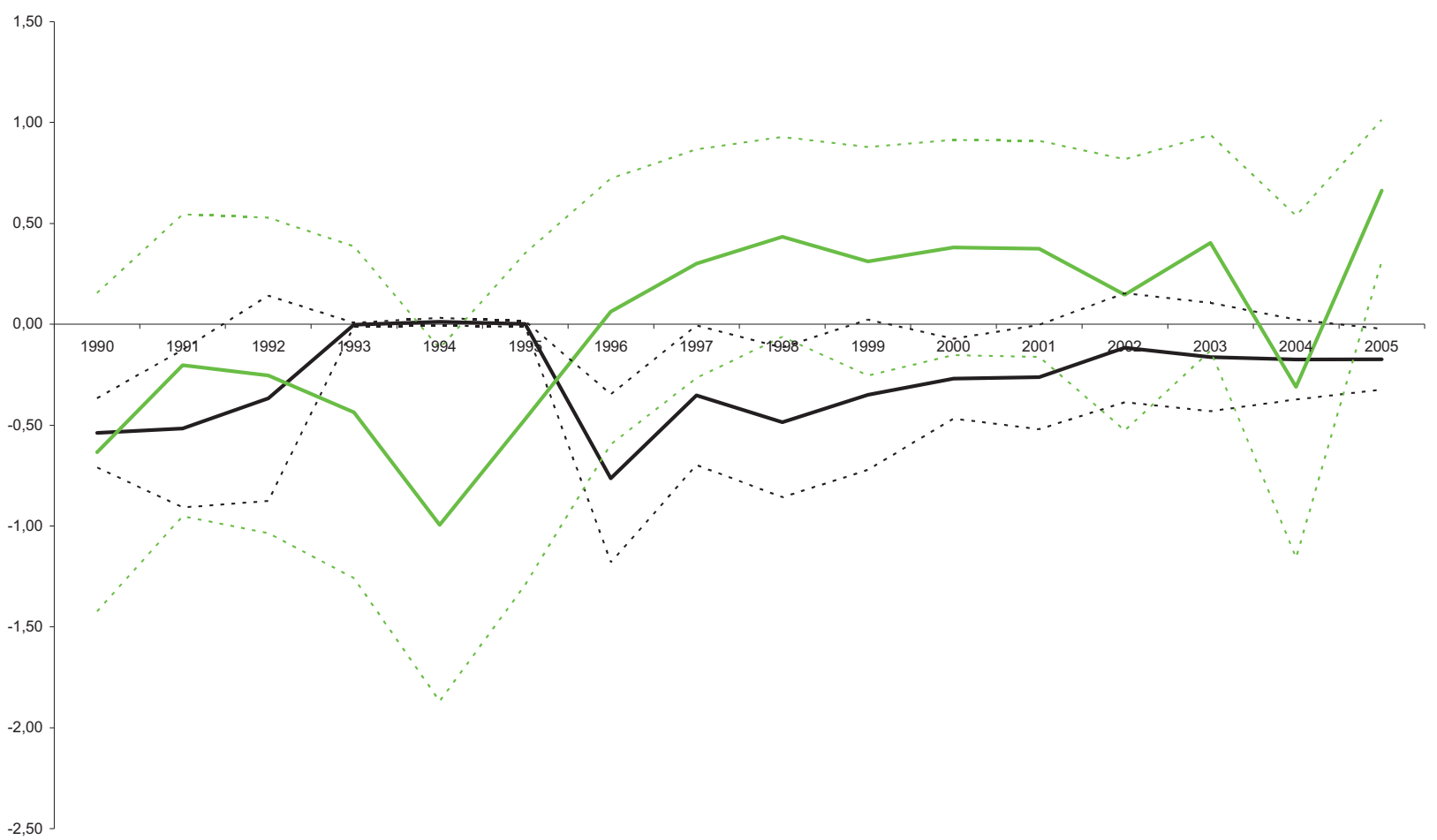

(b) spatial error model

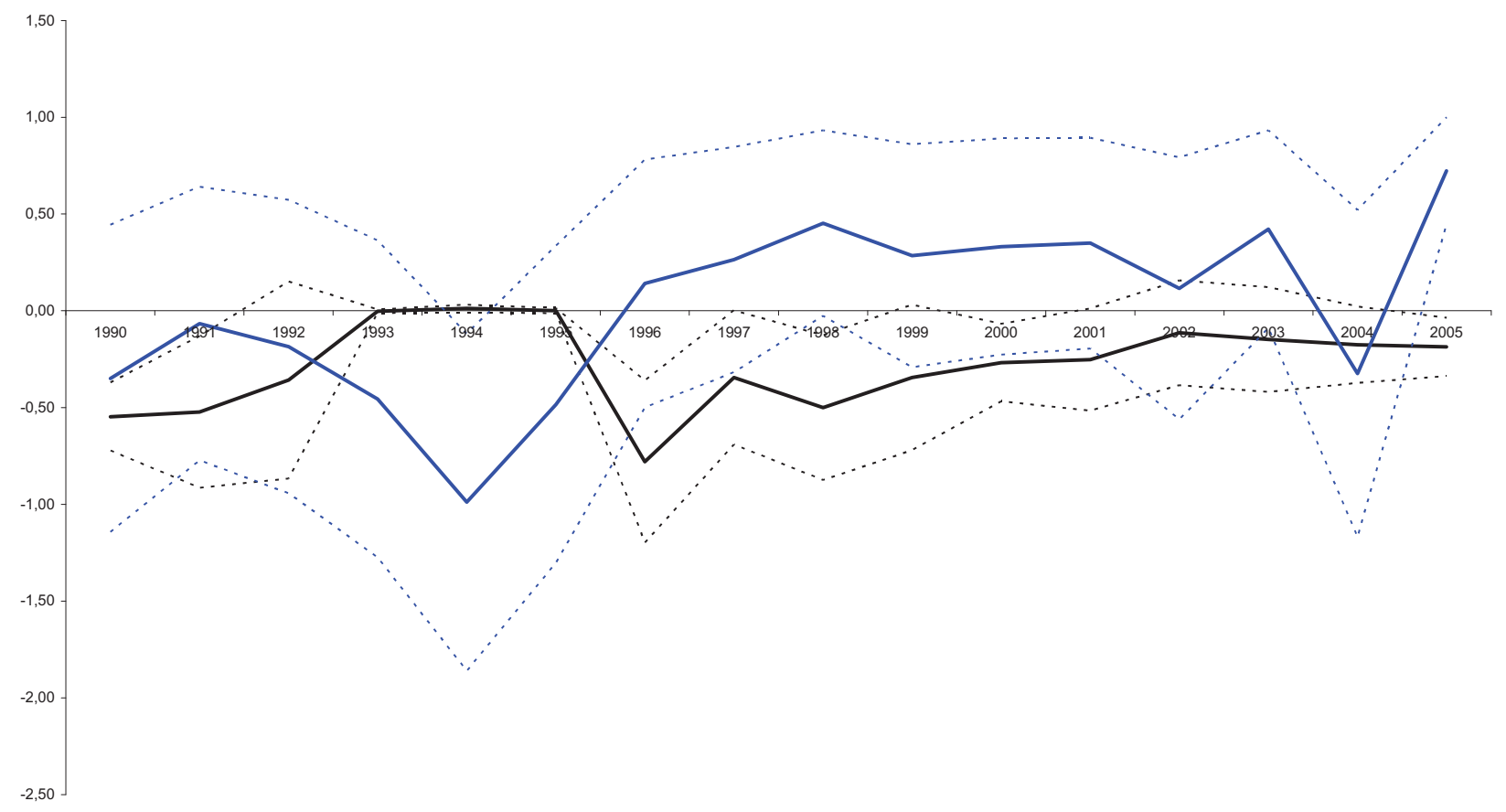

Notes: $-\beta-\rho-\lambda \quad---95 \%$ error bands 


\section{APPENDIX. Data}

Table A.1 Data sources.

\begin{tabular}{|c|c|c|}
\hline series & definition & source \\
\hline interest rate & $\begin{array}{l}1 \text { to } 5 \text { year government } \\
\text { bond yield or } \\
\text { corresponding }(\%)\end{array}$ & $\begin{array}{l}\text { IMF/IFS } \\
\text { Central Banks }\end{array}$ \\
\hline surplus & surplus/GDP ratio (\%) & $\begin{array}{l}\text { IMF General government } \\
\text { Statistics }\end{array}$ \\
\hline public debt & debt / GDP ratio (\%) & $\begin{array}{l}\text { IMF General government } \\
\text { Statistics }\end{array}$ \\
\hline short term interest rate & $\begin{array}{l}\text { central bank, T-bill } 3 \\
\text { months or corresponding } \\
(\%)\end{array}$ & IMF \\
\hline long term interest rate & $\begin{array}{l}10 \text { year government bond } \\
\text { yield or corresponding (\%) }\end{array}$ & IMF \\
\hline GDP per capita & US \$ PPP & Penn World Tables \\
\hline exports & export CIF & IMF Dots \\
\hline imports & import FOB & IMF Dots \\
\hline distance & great circle distance & Matlab \\
\hline common border & & authors \\
\hline dummies & trade agreement & WTO \\
\hline country characteristics & latitude/longitude & Rose (2000) \\
\hline
\end{tabular}

